\title{
Investigation and Assessment of Soil Fertility in Agroforest Landscapes
}

\author{
A I Belyaev¹, A A Tubalov¹, A V Koshelev¹, A M Belyakov¹, and S D Fomin²,3 \\ ${ }^{1}$ Federal Scientific Centre of Agroecology, Complex Melioration and Protective Afforestation of \\ the Russian Academy of Sciences, Volgograd, Russia \\ ${ }^{2}$ Volgograd State Agrarian University, Volgograd, Russia \\ ${ }^{3}$ All-Russian research institute of irrigated agriculture, Timiryazev Street, 9, Volgograd, Russia
}

Abstract

The article presents the research materials of agrochemical properties of soil land use in the agricultural production co-operative "Kolos", Oktyabrsky district of the Volgograd region. The studied agroforestry landscape is located on the left bank of the Tsimlyansk reservoir, in the watershed of the Myshkov River. The territory of the farm is typical for the light chestnut sub -- zone of soils in the South of the Volgograd region. The results of the research are data on agrochemical properties of soils, their analysis and relative assessment, as well as proposals for improving fertility. The analysis of soil

Corresponding Author:

A $V$ Koshelev

fsd_58@mail.ru

Received: 25 October 2019

Accepted: 15 November 2019

Published: 25 November 2019

Publishing services provided by

Knowledge E

(c) A I Belyaev et al. This article is distributed under the terms of the Creative Commons

Attribution License, which permits unrestricted use and redistribution provided that the original author and source are credited.

Selection and Peer-review under the responsibility of the AgroSMART 2019 Conference Committee. samples was carried out in accordance with the guidelines for the comprehensive monitoring of soil fertility of agricultural land. The soil sample was taken from an area of 40 hectares and is a mixed sample composed of 20 individual samples taken from the depth of the arable layer $(0--0.30 \mathrm{~m})$. The total area of the surveyed arable land is 13.3 thousand hectares. Under laboratory conditions, chemical analyses were carried out and such parameters of soil fertility as humus content, content of macronutrients (NPK), content of water-bearing salts, soil granulometric composition, $\mathrm{pH}$ index were determined. Laboratory data are summarized in the table. The analysis of experimental data revealed the ranges of the studied parameters and identified four groups of relative soil fertility: fields with high, medium, low and very low fertility. The grouping of fields based on the account of soil fertility will allow using more differentiated and effective application of the system of measures aimed at increasing the yield and preserving soil fertility.

Keywords: soil granulometric composition, humus content, content of macroelements (NPK), total content of water-soluble salts, soil fertility, system of measures to improve soil fertility, agrolandscapes.

\section{Introduction}

Agrochemical survey materials are an important part of the measures system aimed at land fertility preservation and improvement. Based on the soil parameters monitoring, technologies are being developed for the cultivation of crops and measures to improve the quality and quantity of the products obtained. 
The purpose of the research was to study the state of soil fertility in agricultural landscapes of land use of the agricultural production cooperative (APC) "Kolos", Oktyabrsky district of the Volgograd region and to develop recommendations for its improvement.

\section{Materials and Methods}

The object of research is the territory of the agricultural production co-operative "Kolos" is located to the south of Shebalino, Oktyabrsky district, Volgograd region. The area of the arable land surveyed is 13.3 thousand hectares. The predominant soil type is light chestnut [1].

Works on soil agrochemical surveys were carried out in accordance with the methodology for conducting integrated monitoring of soil fertility of agricultural lands [2--5].

The soil sample was taken from 40 hectares and was a mixed sample composed of 20 individual samples taken with a drill cane to the depth of the arable $(0-0.30 \mathrm{~m})$ layer.

The methods of laboratory analysis of soil samples [6, 7] are: the determination of the soil granulometric composition was carried out according to the Kachinsky method; the determination of the humus content in soil samples was carried out according to the Tyurin method; the determination of hydrolyzable nitrogen was based on the Kornfield method; the determination of mobile forms of phosphorus and potassium according to Machigin in the modification of CINAO; $\mathrm{pH}$ of the aqueous extract by the method CINAO.

The procedure for carrying out a relative assessment is based on statistical procedures for assigning points, weighing points, and final summation [8--12].

\section{Research Results and Discussion}

Figure 1 shows the layout and numbering of fields of the agricultural production cooperative "Kolos". It is an important point in the ongoing research, as it allows comparing the data of agrochemical analyzes with the study area.

Table 1 shows the data of laboratory analysis of selected soil samples by fields of the agricultural production co-operative "Kolos", which characterize the agronomic properties of the studied soils.

The analysis of the table allows concluding that the soil cover of the study area is homogeneous in terms of the soil granulometric composition and is mainly represented by heavy loamy soils. Medium loamy soils are found in four fields, №: 10, 11, 23, 25. 


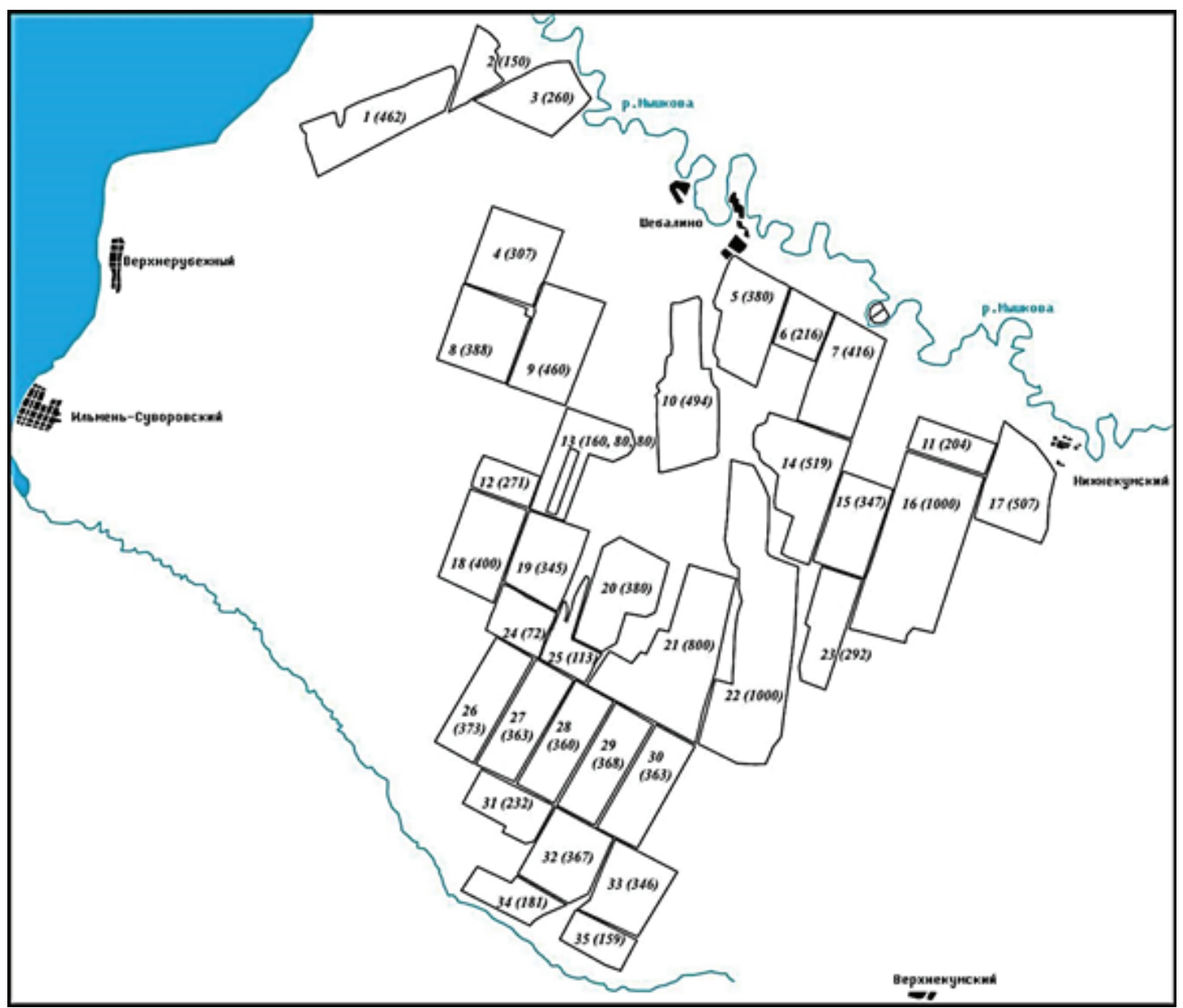

Figure 1: Layout of the APC "Kolos" fields.

Light loamy soils are common in the field located in the floodplain of the river Myshkov, which is used for growing melon and gourds crops.

The analysis of the materials in the table indicates that the parameters of the humus content are in the range from 1.5 to $3 \%$, i.e. all the soil samples studied are low-intensity humic.

It is important to note that in the system of protective forest belts in comparison with the deforested territory, the value of the humus content is more by $0.5--0.7 \%$. On the layout of the fields of the agricultural production co-operative "Kolos", fields № 18, 19, 26--30 can be attributed to these fields.

The presence of nitrogen in soils is closely related to its use by crops and the degree of washing down the soil profile, and also varies greatly throughout the year by season. Therefore, the doses of nitrogen fertilizers need to be adjusted annually using leaf and soil diagnostics.

The analysis of laboratory materials allowed revealing the range of values for the indicator of nitrogen nitrate and ammonium forms amount, it ranges from 16.7 to 26.8 
TABLE 1: Indicators of soil fertility in the fields of APC "Kolos" (depth 0--0.3 m).

\begin{tabular}{|c|c|c|c|c|c|c|c|c|}
\hline № $n / n$ & Area, ha & $\begin{array}{l}\text { Physical } \\
\text { clay, \% }\end{array}$ & $\begin{array}{l}\text { Humus } \\
\text { content, \% }\end{array}$ & $\mathrm{N}_{o .}, \%$ & $\begin{array}{c}\mathrm{P}_{2} \mathrm{O}_{5}, \\
\mathrm{mg} / \mathrm{kg} \text { soil }\end{array}$ & $\begin{array}{l}\mathrm{K}_{2} \mathrm{O} \\
\mathrm{mg} / \mathrm{kg}\end{array}$ & $\begin{array}{l}\text { Dissolved } \\
\text { solids, \% }\end{array}$ & $\mathrm{pH}$ \\
\hline 1 & 462 & 49,73 & 1,79 & 0,041 & 11,2 & 377 & 0,112 & 6 \\
\hline 2 & 150 & 40,71 & 2,38 & 0,056 & 13,1 & 620 & 0,117 & 6 \\
\hline 3 & 260 & 45,44 & 2,03 & 0,042 & 11,9 & 490 & 0,100 & 6 \\
\hline 4 & 367 & 46,91 & 2,04 & 0,059 & 12,3 & 460 & 0,073 & 6 \\
\hline 5 & 380 & 47,67 & 1,96 & 0,060 & 12,7 & 448 & 0,082 & 6 \\
\hline 6 & 216 & 49,21 & 1,96 & 0,041 & 12,0 & 484 & 0,091 & 6 \\
\hline 7 & 416 & 48,17 & 1,86 & 0,057 & 10,1 & 446 & 0,093 & 6 \\
\hline 8 & 388 & 45,18 & 2,08 & 0,059 & 11,6 & 436 & 0,079 & 7 \\
\hline 9 & 460 & 49,48 & 1,92 & 0,052 & 12,8 & 466 & 0,068 & 7 \\
\hline 10 & 494 & 44,06 & 1,91 & 0,041 & 12,0 & 526 & 0,093 & 6 \\
\hline 11 & 204 & 43,63 & 2,15 & 0,042 & 12,6 & 369 & 0,106 & 6 \\
\hline 12 & 271 & 49,00 & 1,79 & 0,041 & 12,1 & 418 & 0,110 & 6 \\
\hline 13 & 320 & 46,2 & 1,97 & 0,044 & 12,6 & 409 & 0,118 & 6 \\
\hline 14 & 519 & 46,58 & 1,85 & 0,062 & 12,1 & 426 & 0,076 & 6 \\
\hline 15 & 347 & 47,92 & 2,15 & 0,040 & 12,8 & 481 & 0,104 & 6 \\
\hline 16 & 1000 & 47,47 & 2,15 & 0,041 & 13,0 & 436 & 0,106 & 6 \\
\hline 17 & 507 & 48,49 & 1,43 & 0,043 & 12,9 & 392 & 0,092 & 6 \\
\hline 18 & 400 & 50,50 & 2,11 & 0,040 & 13,2 & 463 & 0,097 & 6 \\
\hline 19 & 345 & 49,40 & 2,11 & 0,040 & 13,3 & 454 & 0,114 & 5 \\
\hline 20 & 380 & 49,17 & 1,64 & 0,052 & 13,8 & 428 & 0,075 & 6 \\
\hline 21 & 800 & 48,13 & 2,26 & 0,067 & 10,2 & 430 & 0,075 & 6 \\
\hline 22 & 1000 & 47,42 & 1,73 & 0,050 & 14,7 & 418 & 0,102 & 6 \\
\hline 23 & 292 & 44,33 & 2,0 & 0,048 & 10,4 & 400 & 0,102 & 6 \\
\hline 24 & 72 & 51,09 & 1,73 & 0,058 & 9,8 & 424 & 0,114 & 6 \\
\hline 25 & 113 & 44,97 & 1,86 & 0,056 & 10,6 & 440 & 0,096 & 6 \\
\hline 26 & 373 & 48,25 & 2,43 & 0,056 & 10,8 & 535 & 0,099 & 6 \\
\hline 27 & 363 & 49,17 & 2,33 & 0,051 & 11,4 & 454 & 0,091 & 6 \\
\hline 28 & 360 & 47,88 & 2,11 & 0,054 & 11,6 & 346 & 0,110 & 6 \\
\hline 29 & 368 & 49,99 & 2,03 & 0,044 & 11,0 & 369 & 0,102 & 6 \\
\hline 30 & 363 & 46,79 & 2,04 & 0,041 & 10,5 & 382 & 0,072 & 6 \\
\hline 31 & 232 & 46,09 & 2,20 & 0,052 & 10,1 & 412 & 0,088 & 7 \\
\hline 32 & 367 & 47,76 & 1,64 & 0,053 & 9,5 & 404 & 0,090 & 6 \\
\hline 33 & 346 & 48,88 & 2,41 & 0,060 & 13,1 & 416 & 0,084 & 6 \\
\hline 34 & 181 & 46,30 & 1,89 & 0,052 & 10,4 & 427 & 0,076 & 7 \\
\hline 35 & 159 & 47,04 & 1,97 & 0,045 & 10,9 & 440 & 0,068 & 6 \\
\hline 36 & 30 & 25,79 & 2,37 & 0,078 & 11,8 & 320 & 0,143 & 6 \\
\hline
\end{tabular}

mg per $\mathrm{kg}$. The minimum value corresponds to the field № 35 (159 ha), and the maximum to field № 2 (150 ha). 
The absolute values of the nitrogen content in the averaged samples by fields make it possible to classify the samples into nitrogen supply groups. All fields can be attributed to one of two groups -- medium and good supply.

The phosphorus content in the soil is a major factor in determining the planned yield of agricultural crops. It participates in photosynthesis reactions, in respiration and cell division, in energy transfer, it is part of proteins and nucleic acids. Phosphorus is necessary for plants at all stages of development, but is most intensively used from the beginning of the growing season in the period from tillering to flowering in cereals. Therefore, it is recommended applying a part of phosphorus-containing fertilizers together with sowing of seeds [13].

When phosphorus starvation, red-but-purple hues appear in the color of the leaves. For the formation of 1 ton of grain production, $12--14 \mathrm{~kg}$ of phosphorus is required, and for technical ones, from $30 \mathrm{~kg}$ for sunflower seeds and up to $50 \mathrm{~kg}$ for mustard.

The analysis of laboratory data allowed revealing the range of phosphorus indicator values in averaged samples, it has an interval from 9.5 to $14.7 \mathrm{mg} / \mathrm{kg}$. All analyzed samples, with the exception of two fields, can be attributed to the low supply. The fields number 24 and 32 belong to the security group -- very low.

When planning agricultural works, priority is given to the placement of the most valuable crops, the optimal time for vapor processing, etc. must be given to fields with a high content of phosphorus able to give the greatest economic effect.

The analysis of laboratory materials, by potassium content, makes it possible to classify all the investigated samples as high and higher potassium content samples (range of values 380--520 mg/kg).

Potassium enters plants with great intensity from the beginning of the growing season to flowering. It contributes to the normal course of photosynthesis, the accumulation of fats and carbohydrates, stimulates grain loading, increases the resistance of plants to lodging, fungal diseases, drought and low temperatures. Sunflower is especially demanding on potash nutrition [8].

Table 1 presents the data characterizing the content of water-soluble salts (and $\mathrm{pH}$ index) in the averaged samples, according to the fields selected in the studied area.

The analysis of the table shows that the values of the dense residue index are in the range from 0.068 to $0.143 \%$. This range shows that the indicator under study varies significantly in the fields (more than 2 times), but in the place where its absolute values do not exceed the toxicity threshold and all soils can be classified as non-saline. 
The fertility final assessment was carried out on the basis of the procedures of the ball assessment and the values of five indicators -- the content: humus (\%); nitrogen $(\mathrm{mg} / \mathrm{kg})$, phosphorus $(\mathrm{mg} / \mathrm{kg}$ ), potassium $(\mathrm{mg} / \mathrm{kg}$ ), water-soluble salts (\%). The value of the index, which most closely corresponds to the maximum fertility, received the highest score of 3 , and in the smallest of 1 , the fields having the value of the intermediate range indicator received a rating of 2 .

Scoring weighing procedure allows comparing indicators with different significance (contribution) to the final grade. In the final summation, the content of substances was carried out with the following coefficients: phosphorus content -- 3 , humus -- 2 , nitrogen, potassium, water-soluble salts -- coefficient 1.

The total amount of points has a range of values from 9 to 22 points. The whole range was divided into four intervals -- groups of relative soil fertility:

1. from 9 to 12 points -- very low fertility, fields № $24,25,32$;

2. from 12 to 15 points -- low fertility, fields № 1, 5, 7.12, 13, 17, 23, 26, 28, 29.30, 31;

3. from 15 to 18 points -- average fertility, fields № $3,6,8,9,10,11,14,15,20,22,27$;

4. from 18 to 22 points -- high fertility, fields № $2,4,16,18,19,33$.

The soil fertility assessment is important for the development of standard solutions aimed at preserving soil fertility and increasing the yield of cultivated crops.

The analysis and comparison of the location in the relief, fields included in different groups of soil fertility allows revealing the reasons for the low fertility of individual territories -- the development of erosion processes, the complexity of the soil cover -- the presence of saline soils. Therefore, the Figure 2 shows an image of two fields included in the first and fourth groups of soil fertility.

The fields of high fertility group assess the relative soil fertility (Figure 6A, field № 3) indicates a single manifestation of erosion degradation linear forms, but the image of the field included in the group of very low fertility (Figure 6B, field № 32) shows a significant development of aqueous degradation linear forms. The number of the gullies vertices located on this field is $11 \mathrm{pcs}$. The degradation linear forms are closely related to the processes of plane washout and the loss of humus of the upper soil layers.

Reclamation measures to improve the fertility of the fields included in the "very low fertility" group in order to be effective must be comprehensive, and include, along with the use of fertilizers, organizational and forest reclamation activities. 

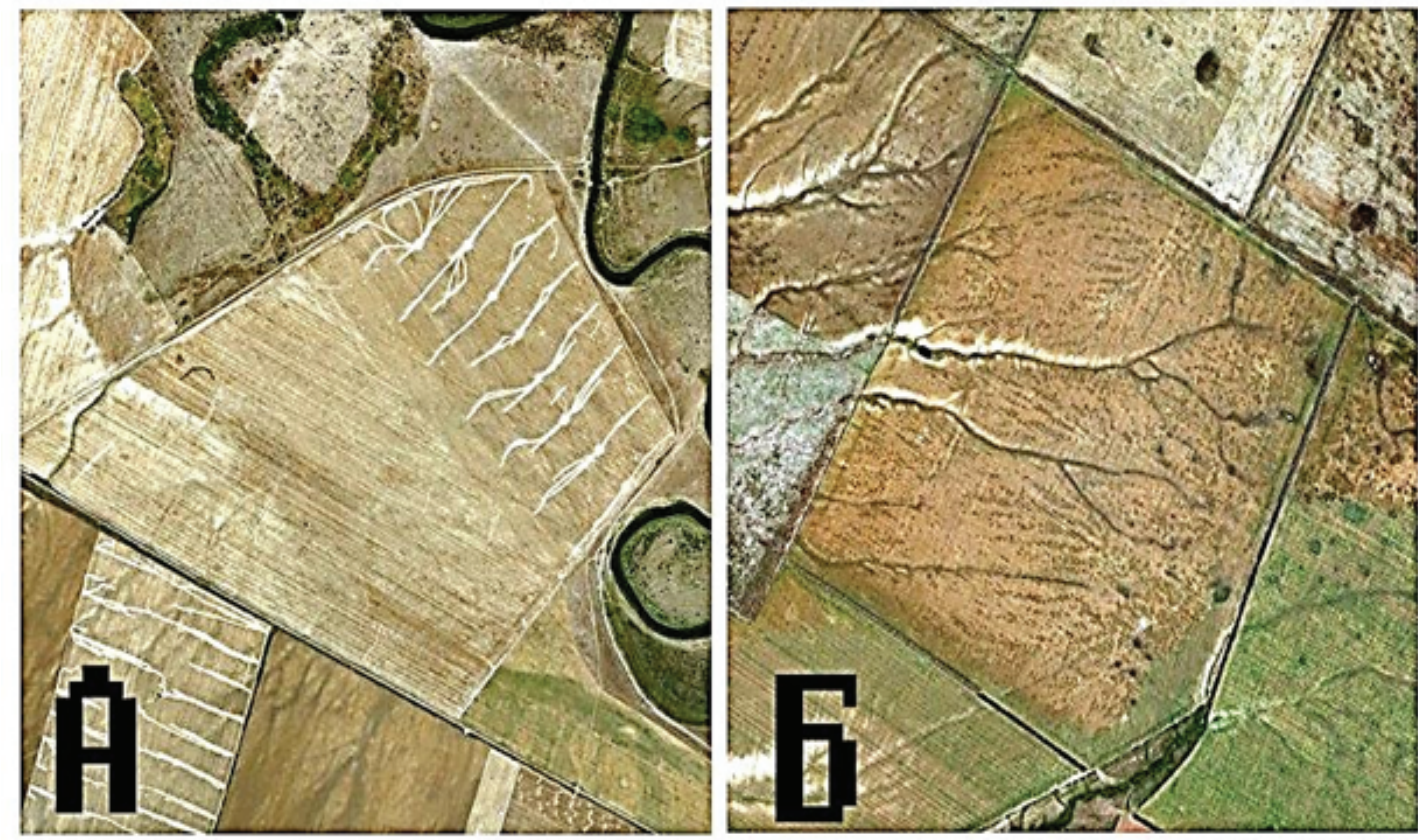

Figure 2: Image of the fields (A) № 3 (260 hectares) and (B) № 32 (367 hectares) in the satellite images.

\section{Conclusion}

The soils of the agricultural production co-operative "Kolos" in the Oktyabrsky district, Volgograd region are typical for light-chestnut soils: a little low-humic, solonetzic, and low fertile for grain and other crops. To ensure the growth of crop yields and the preservation of soil fertility on the farm, it is necessary to develop a system for applying organic and mineral fertilizers.

A complex of agrochemical and agrotechnical measures is necessary to increase the existing fertility. Measures should not be a one-time, but systemic ones. The fertilizer system should include a set of both mineral and organic fertilizers with the obligatory use of micronutrients against the background of agrotechnology acceptable to the zone of dry farming.

\section{Funding}

The research was performed in accordance with the State Task No. 0713-2016-0508 "Development of conceptual, methodological and informational and technological bases for the formation of environmentally balanced agroforest landscapes and adaptive farming systems using new generation chemicals for precision crop production 
while maintaining and reproducing soil fertility and efficient use Natural Resource Potential" of the Federal Science Center of Agroecology RAS.

\section{Acknowledgement}

The authors would like to express gratitude to their colleague for their contribution and support to the research. They are also grateful to all the reviewers who gave their valuable inputs to the manuscript and helped in completing the paper.

\section{Conflict of Interest}

The authors have no conflict of interest to declare.

\section{References}

[1] Kulik, K.N., Kretinin, V.M., Rulev, A.S., Shishkunov V.M. (2017). The Red Book of Soils of the Volgograd Region. Volgograd: FSC of Agroecology RAS.

[2] Belyakov, A.M., Tubalov, A.A., Koshelev, A.V. (2018). State and measures to improve the fertility of light chestnut soils in agro-forest landscapes. Proceedings of the Nizhnevolzhsky Agro-University Complex: Science and Higher Professional Education, vol. 2(50), pp. 30--36.

[3] Vitkovskaya, S.E., Hoffman, O.V. (2013). Assessment of the ecological status of agroecosystems (on the example of field experience). Bulletin of St. Petersburg University, Series 3. Biology, vol. 1, pp. 102--112.

[4] Derzhavin, L.M., Fried, A.S. (2012). Scientific and methodological principles of integrated monitoring of agricultural land fertility. Agrochemistry, vol. 2, pp. 3--11.

[5] Zhigulina, T.N., Meretsky, V.A. (2016). Methodical aspects of the inventory of agricultural land used by agricultural organizations. Altai State Agrarian University Bulletin, vol. 8(142), pp. 84--88.

[6] Pansu, M., Gotera, J. (2014). Soil analysis. Handbook. Mineralogical, organic and inorganic methods of analysis, per. 2nd Eng. ed. by ed. D.A. Pankratova. St. Petersburg, SPb.: CSC "Profession".

[7] Shein, E.V., Madi, A.I. (2018). Soil particle size distribution: methods of laser diffraction and sedimentometry, their comparison and use. Agrochemical Bulletin, vol. 1, pp. 9$-11$. 
[8] Dospekhov, B.A. (2011). Methodology of field experience: (with the basics of statistical processing of research results). Moscow: Alliance.

[9] Klebanovich, N.V., Kindeev, A.L. (2018). Geostatistical assessment of the variability of soil properties. Bulletin of Udmurt University. Biology series. Earth Sciences, vol. 28, no. 1, pp. 91--102.

[10] Douaik, A., Meirvenne, V., Toth, T. (2011). Statistical Methods for the analysis of soil spatial and temporal variability. Principles, Application and Assessment in Soil Science. London: IntechOpen, pp. 279--308.

[11] Leopizzi, S., Gondret, K., Boivin, P. (2018). Spatial variability and sampling requirements of the visual evaluation of soil structure in cropped fields. Geoderma, vol. 314, pp. 58--62.

[12] Oliver, M.A., Webster, R. (2015). Basic Steps in Geostatistics: The Variogram and Kriging. SpringerBriefs in Agriculture.

[13] Ovchinnikov, A.S., Borisenko, I.B., Pleskachev, Yu.N. (2011). Programming the productivity of agricultural crops in their cultivation using innovative technologies. Volgograd: IPK FGBOU VPO Volgograd State Agricultural Academy "Niva". 